\title{
Dental Students' Perception and Confidence Level in Key Dental Procedures for General Practice and the Impact of Competency Implementation On Their Confidence Level, Part I (Prosthodontics and Conservative Dentistry)
}

\section{Wijdan R. Elmanaseer}

The University of Jordan

\section{Salah Al-Omoush}

The University of Jordan

Firas Alsoleihat ( $\nabla$ firas.alsoleihat@ju.edu.jo )

The University of Jordan

\section{Research Article}

Keywords: level of confidence, key dental procedures, competency-based assessment system, prosthodontic procedures, conservative dentistry procedures, dental education

Posted Date: September 28th, 2021

DOl: https://doi.org/10.21203/rs.3.rs-851058/v1

License: (c) (1) This work is licensed under a Creative Commons Attribution 4.0 International License. Read Full License 


\section{Abstract}

Background: There are limited studies that assess the level of confidence among the final year dental students in the ability to conduct key dental procedures. The present study aims to assess the perception and confidence level of final year dental students from the School of Dentistry at the University of Jordan to perform essential dental procedures across various dental disciplines; to assess the effect of competencies implementation in curricula on the confidence level of students.

Methods: An electronic questionnaire was answered by two cohorts of final year dental students: one group in 2016 before the implementation of the competency-based assessment system (group 1, n = 153), and the other in 2019 after the implementation of this system (group 2, $n=199$ ). The two groups were compared regarding the degree of confidence in conducting key dental procedures. The data were analysed using SPSS statistics. Statistical significance was set at 0.05 level.

Results: Statistically significant differences between the two groups regarding the confidence levels were found in 5 out of 20 prosthodontic procedures (placing treatment plan of removable partial dentures, using semi-adjustable articulator, giving oral hygiene instructions (OHIs) for denture patients, dealing with complete denture post-insertion complaints, and giving OHIs for denture patients); and in 5 out of 20 conservative Dentistry procedures (placing treatment plan of removable partial dentures (RPD), using semi-adjustable articulator, giving OHI's for Denture Patients, dealing with complete denture (CD) postinsertion complaints and giving OHI's for Denture patients). These differences were in favor of grope 2 .

Conclusion: This study has shown that final year dental students generally have high confidence levels in doing simple dental procedures and less confidence in more complex ones, thus additional focus on such complex procedures is advised during post-graduation training and before entitlement for practice licensing.

Competency-based dental education is an advantageous over classical dental training systems, and thus should be maintained and continuously enhanced.

\section{Introduction}

During their education journey, dental students are gradually go through stepwise phases of education starting from the theoretical part, then followed by the pre-clinical part, and ending with the clinical education. This will ensure students develop necessary knowledge and expertise to become dentists having sufficient capabilities to practice safely in their career [1]. Throughout the educational process, the evaluation of the students is very crucial to assess the effectiveness of the education provided and the degree of achievement of the intended objectives of learning. The teaching and evaluation strategies need to be in harmony with the intended learning outcomes which are usually grounded on the necessities of clinical reality, so that effective education can be realized [2]. The implementation of competencies in the curricula of undergraduate dental students was to support their process of development, and as tool to update and develop curricula [3-7]. Internationally, competency profiles may 
have slight differences between different dental schools, however, they all share common core competencies that are designed to ensure both independent and safe clinical practice [8]. These shared competencies normally consists of the ability to deal with clinical and scientific knowledge, the ability to communicate, having social skills, the ability to diagnose and to make a treatment plan, the ability to take care for the patient, the ability to promote health and prevention, and having a professional attitude [9].

As mentioned earlier, the need to evaluate the level of dental student's competence is crucial for validating their effectiveness after graduation. With the continuous introduction of new scientific knowledge, the markers for the level of competencies are continuously questioned, thus the need to constantly restructure the requirements required to obtain competencies. Nowadays, new clinical challenges are facing the newly graduate students, hence they are often required to perform invasive or non-invasive and often non-reversible surgical procedures using sophisticated materials and equipment within a shorter time frame [10]. This exerts more stress on the graduating dentists, as they are expected not only to be attentive to patient's needs, but also to learn the new skills required to treat them appropriately [11]. Consequently, it is important to assess the confidence levels of dental students especially seniors regarding key important dental procedures.

In addition to the quality of education, clinical experience plays an essential role in determining the confidence level of dental students [12]. Although studies have revealed varying results, but some showed that dental students lacked significant amount of confidence when performing complicated dental procedures [13]. However, this confidence level increased when students gained more experience and training [14].

In the past few years, some dental institutions as long as other human science schools have encountered many challenges, these challenges including the increased number of enrolled students that surpassed the capacity of the available units. Moreover, the limited availability of patients that negatively affected the level of the clinical and preclinical student's training [15]. All of the previous conditions have put our dental institution in a challenge to sustain the intended level education and training for its students. In the dental school of the University of Jordan, dental students need five years of successful continuous studying to graduate, they have the preclinical laboratory training at year three, then at year four they start their clinical training, however, the majority of clinical requirements and competencies are in their final year which is the fifth year.

There is limited information regarding the way students perceive competencies and their confidence level in various dental procedures. Until now, in Jordan limited studies has been conducted to assess the confidence levels of dental students regarding various dental procedures, procedures which are needed by freshly graduates to practice as a general practitioner from different dental specialties. Moreover, no studies to compare the student's confidence level throughout time. Therefore, the present study aimed to assess the perception and confidence level of final year dental students from the School of Dentistry at the University of Jordan to perform essential dental procedures from core dental disciplines; Prosthodontics, Conservative, Endodontics, Radiology, Pediatrics, Orthodontics, Periodontics, and Oral 
Surgery. The second aim is to assess the effect of competencies implementation in curricula on the confidence level of students. This part will assess only Prosthodontics and conservative dental procedures, part two of this study will deal with the rest. It is a comparative study between 2019 where students have to complete competencies to succeed and 2016 where competencies were not implemented in their curriculum.

\section{Methods}

\section{Data collection}

This study was carried out in two stages; stage one was conducted at the end of the academic year of $2015 / 2016$ (competencies were notpart of the curriculum), all fifth-year dental graduates $(N=153)$ were asked to complete a questionnaire. Then at the end of the academic year 2019/2020 (Competencies were part of the curriculum) the same questionnaire was generated again using Google Forms and sent to all fifth-year dental graduates and they were asked to fill it $(N=199)$.

The questionnaire items were based on the main required clinical skills and competencies from core dental specialties; Prosthodontics, Conservative, Endodontics, Pediatrics, Oral Surgery, Orthodontics, Periodontics, and Radiology. Accordingly, the questionnaire divided into eight sections, each section was related to the chosen discipline as the following, Prosthodontics (20 questions), Conservative (16 questions), Endodontics (9 questions), Radiology (4 questions), Pediatrics (12 questions), Orthodontics (7 questions), Oral Surgery (15 questions), and Periodontics (9 questions). The questions were designed to assess the students' self-confidence level in carrying out the intended clinical tasks. The responses were reported on a five-point scale Likert scale from (strongly confident, confident, neutral, not confident and strongly not confident). Please add up the psychometric properties of the questionnaire (validity and reliability of the measurement tool).

\section{Ethical approval}

This study was approved by the Institutional Review Board/Deanship of Scientific Research of the University of Jordan (Ref \# 9-2019). Before the students filled the questionnaire, the questionnaire stated that the participants were not held obliged to complete and return the forms and completion of the survey would have no influence on their overall academic grading or performance. To maintain the anonymity, no personal identifiers were used in the online questionnaire.

\section{Data Analysis}

A questionnaire was first conducted on a small sample to test the instruments' psychometric properties and to discover difficulties that might be encountered during the actual data collection, and to check the tools' convenience to Jordanian culture. Pilot study helped determining the time needed for the participants to fill the self-reported questionnaire, readiness, and clearness of tools' items. The piloting was carried out using the responses of $5 \%$ of the actual study sample size. 
Data was collected, codded and screened for completeness before entering the computer program. The analysis was performed by using Statistical Package for Social Science (SPSS) version 22; alpha level of 0.05 was used for determining statistical significance. The distribution of the variables was reviewed for skewed distribution. Two types of analysis were used: descriptive statistics and inferential analysis. Descriptive statistics used to estimate frequencies, mean, median, mode, standard deviation and percentages according to the level of variables. Inferential analysis used to assess the effect of competencies implementation in curricula on the confidence level of students. Levene's Test for Equality of Variances and t-test for Equality of Means were conducted to compare both samples and to insure normal distribution.

\section{Results}

\section{Students' Perception and Confidence Level in Prosthodontics}

A total of 352 fifth year dental students were included in the study (153 from 2016 and 199 from 2019). Level of confidence was rated using five point Likert scale. Descriptive statistics was carried out for both samples (Table 1, Fig. 1 a \& b, Fig. 2 a \& b).

In both 2016 and 2019, student felt extremely confident and confident mainly in the simple prosthodontic procedures; provide patients with Complete Dentures (CD) (72\% and $65 \%$ respectively), provide patients with Co-Cr RPD (70\% and 58\% respectively), provide patient with Acrylic RPD (66\% and 43\% respectively), Treatment Plan for partially edentulous patient (73\% and 50\% respectively), diagnosing denture induced stomatitis ( $65 \%$ and $58 \%$ respectively), giving OHI's ( $85 \%$ and $72 \%$ respectively), dealing with CD postinsertion complaints ( $73 \%$ and $62 \%$ respectively), giving post-insertion instructions for removable prosthesis (83\% and 67\% respectively) (Table 1, Fig. 1 a \& b, Fig. 2 a \& b). However, students were less confident in other prosthodontic procedures like, surveying study cast for RPD planning ( $48 \%$ and $39 \%$ respectively), dealing with Geriatric patients ( $40 \%$ and $38 \%$ respectively), lab steps for CR-Co RPD ( $45 \%$ and $40 \%$ respectively), familiarity with implant retained CD and RPD (31\% for both years), clinical repairing of Acrylic Dentures (28\% and $30 \%$ respectively), and relining \& rebasing of CD (34 for both years). On the other hand, students were extremely not confident and not confident in the more complicated Prosthodontic procedures; using Arbitrary Face-bow (61\% and 50\% respectively), provide patient with Immediate Dentures (43\% and 59\% respectively) and provide patient with Over Denture (45\% and $54 \%$ respectively) (Table 1, Fig. 1 a \& b, Fig. 2 a \& b).

Comparing the two years, there was no significant difference between the confidence levels at different procedures, except for Placing treatment plan of RPD, using semi-adjustable articulator, giving OHI's for Denture Patients, dealing with CD post-insertion complaints and giving OHI's for Denture patients ( $P$ $<.05)$. Although, in using semi-adjustable articulator $41 \%$ of students in 2016 were mainly extremely not confident and not confident, while in 2019 41\% of them were mainly neutral, also in providing patients with Copy Dentures and in lab steps for fixed prosthesis, students in 2016 were almost neutral and 
extremely not confident and not confident at almost the same percent, while in $201940 \& 42 \%$ of them were extremely not confident and not confident.

Table1 Comparison of the level of confidence in the ability to conduct key prosthodontic procedures between group 1 and group 2 


\begin{tabular}{|c|c|c|c|c|c|}
\hline Procedure & Year & $n$ & Mean & $S D$ & Std. Error Mean \\
\hline \multirow[t]{2}{*}{ Lab steps for Fixed Prosthethesis } & 2016 & 153 & 2.84 & 1.165 & .094 \\
\hline & 2019 & 192 & 2.74 & 1.233 & .089 \\
\hline \multirow[t]{2}{*}{ Treatment Plan for Partially Edentulous Patient } & 2016 & 153 & 3.83 & 1.056 & .085 \\
\hline & 2019 & 191 & 3.34 & 1.149 & .083 \\
\hline \multirow[t]{2}{*}{ Using Semi-Adjustable Articulator } & 2016 & 153 & 2.73 & 1.262 & .102 \\
\hline & 2019 & 191 & 2.92 & 1.158 & .084 \\
\hline \multirow[t]{2}{*}{ Using an Arbitrary Face-bow transfer } & 2016 & 153 & 2.25 & 1.253 & .101 \\
\hline & 2019 & 192 & 2.44 & 1.205 & .087 \\
\hline \multirow[t]{2}{*}{ Surveying study cast for RPD planning } & 2016 & 153 & 3.44 & 1.164 & .094 \\
\hline & 2019 & 192 & 3.15 & 1.132 & .082 \\
\hline \multirow[t]{2}{*}{ Provide patient with Acrylic RPD } & 2016 & 153 & 3.70 & 1.193 & .096 \\
\hline & 2019 & 193 & 3.23 & 1.133 & .082 \\
\hline \multirow[t]{2}{*}{ Provide patient with Co-Cr RPD } & 2016 & 153 & 3.77 & 1.109 & .090 \\
\hline & 2019 & 193 & 3.56 & 1.079 & .078 \\
\hline \multirow[t]{2}{*}{ Provide patient with Complete Dentures (CD) } & 2016 & 153 & 4.16 & 1.115 & .090 \\
\hline & 2019 & 191 & 3.72 & 1.143 & .083 \\
\hline \multirow[t]{2}{*}{ Provide patient with Copy Dentures } & 2016 & 153 & 2.82 & 1.236 & .100 \\
\hline & 2019 & 191 & 2.69 & 1.172 & .085 \\
\hline \multirow[t]{2}{*}{ Provide patient with Immediate Dentures } & 2016 & 153 & 2.67 & 1.322 & .107 \\
\hline & 2019 & 192 & 2.32 & 1.215 & .088 \\
\hline \multirow[t]{2}{*}{ Provide patient with Over Dentures } & 2016 & 153 & 2.50 & 1.165 & .094 \\
\hline & 2019 & 189 & 2.37 & 1.139 & .083 \\
\hline \multirow[t]{2}{*}{ Relining and Rebasing CD } & 2016 & 153 & 3.01 & 1.259 & .102 \\
\hline & 2019 & 188 & 2.98 & 1.204 & .088 \\
\hline \multirow[t]{2}{*}{ Clinical Repairing of Acrylic Denture } & 2016 & 153 & 2.91 & 1.216 & .098 \\
\hline & 2019 & 190 & 2.86 & 1.228 & .089 \\
\hline \multirow[t]{2}{*}{ Giving Pll's of Removable Prosthesis } & 2016 & 153 & 4.12 & .993 & .080 \\
\hline & 2019 & 190 & 3.82 & 1.223 & .089 \\
\hline
\end{tabular}




\begin{tabular}{llllll} 
Dealing with CD post-insertion complaints & 2016 & 153 & 3.97 & .949 & .077 \\
\cline { 2 - 6 } & 2019 & 190 & 3.76 & 1.086 & .079 \\
\hline Giving OHI's for Denture Patients & 2016 & 153 & 4.17 & .979 & .079 \\
\cline { 2 - 6 } & 2019 & 191 & 3.95 & 1.137 & .082 \\
\hline Diagnosing Denture Induced Stomatitis & 2016 & 153 & 3.77 & 1.127 & .091 \\
\cline { 2 - 6 } & 2019 & 189 & 3.66 & 1.112 & .081 \\
\hline Lab steps of Co-Cr RPD & 2016 & 153 & 3.27 & 1.253 & .101 \\
\hline Dealing with Geriatric Patients & 2019 & 189 & 3.18 & 1.194 & .087 \\
\hline Familiarity with Implants retained CD and RPD & 2016 & 153 & 2.86 & 1.178 & .095 \\
\cline { 2 - 6 } & 2019 & 189 & 3.09 & 1.152 & .084 \\
\hline
\end{tabular}

\section{Students' Perception and Confidence Level in Conservative dentistry}

A total of 352 fifth year dental students were included in the study (153 from 2016 and 199 from 2019). Level of confidence was rated using five point Likert scale. Descriptive statistics was done for both samples (Table2, Fig 3 a \& b, Fig 4 a \& b).

Generally, students were extremely confident and confident in multiple simple routine conservative procedures in both years 2016 and 2019, for example, placing posterior composite (89\% and $71 \%$ respectively), placing matrix band ( $83 \%$ and $60 \%$ respectively) there was a significant difference between the two years $(P<.05)$. placing anterior composite ( $89 \%$ and $74 \%$ respectively), placing posterior amalgam ( $85 \%$ and $74 \%$ respectively), single crown PFM ( $77 \%$ and $70 \%$ respectively), three units' bridge (74\% and $65 \%$ respectively). However, students were less confident in more complex conservative procedures in both 2016 and 2019 like; placing fiber-post (52\% and $41 \%$ respectively), management of pulp exposure ( $55 \%$ and $51 \%$ respectively), placing prefabricated post ( $50 \%$ and $33 \%$ respectively), bleaching of vital teeth (38\% and 30\% respectively). While in 2016 and 2019 students were extremely not confident and not confident in advanced procedures like; Inlay (61\% and $42 \%$ respectively), Only (62\% and $41 \%$ respectively), Resin Bonded Bridge ( $41 \%$ and $39 \%$ respectively), Veneers ( $42 \%$ and $36 \%$ respectively) and placing Indirect cast-post (49\% and 52\% respectively) (Table2, Fig 3 a \& b, Fig 4 a \& b).

Table2 Comparison of the level of confidence in the ability to conduct key conservative dentistry procedures between group 1 and group 2 


\begin{tabular}{|c|c|c|c|c|c|}
\hline Procedure & Year & $n$ & Mean & $S D$ & Std. Error Mean \\
\hline \multirow[t]{2}{*}{ Posterior Amalgam } & 2016 & 153 & 4.29 & 1.068 & .086 \\
\hline & 2019 & 191 & 4.02 & 1.218 & .088 \\
\hline \multirow[t]{2}{*}{ Anterior Composite } & 2016 & 153 & 4.41 & 1.029 & .083 \\
\hline & 2019 & 193 & 4.12 & 1.143 & .082 \\
\hline \multirow[t]{2}{*}{ Posterior Composite } & 2016 & 153 & 4.43 & 1.018 & .082 \\
\hline & 2019 & 191 & 3.88 & 1.247 & .090 \\
\hline \multirow[t]{2}{*}{ Bleaching of Vital Teeth } & 2016 & 153 & 3.18 & 1.273 & .103 \\
\hline & 2019 & 188 & 2.79 & 1.355 & .099 \\
\hline \multirow[t]{2}{*}{ Placing Matrix Band for Class II } & 2016 & 153 & 4.24 & 1.037 & .084 \\
\hline & 2019 & 188 & 3.71 & 1.277 & .093 \\
\hline \multirow[t]{2}{*}{ Direct cast-post } & 2016 & 153 & 2.84 & 1.338 & .108 \\
\hline & 2019 & 189 & 2.60 & 1.219 & .089 \\
\hline \multirow[t]{2}{*}{ Indirect cast-post } & 2016 & 153 & 2.44 & 1.129 & .091 \\
\hline & 2019 & 189 & 2.45 & 1.098 & .080 \\
\hline \multirow[t]{2}{*}{ Prefabricated post } & 2016 & 153 & 3.34 & 1.247 & .101 \\
\hline & 2019 & 191 & 2.88 & 1.227 & .089 \\
\hline \multirow[t]{2}{*}{ Fiber-post } & 2016 & 153 & 3.45 & 1.251 & .101 \\
\hline & 2019 & 191 & 3.34 & 3.072 & .222 \\
\hline \multirow[t]{2}{*}{ PFM single crown } & 2016 & 153 & 3.95 & 1.069 & .086 \\
\hline & 2019 & 190 & 3.81 & 1.062 & .077 \\
\hline \multirow[t]{2}{*}{ Three units Bridge } & 2016 & 153 & 3.89 & 1.067 & .086 \\
\hline & 2019 & 188 & 3.67 & 1.043 & .076 \\
\hline \multirow[t]{2}{*}{ Veneers } & 2016 & 153 & 2.68 & 1.173 & .095 \\
\hline & 2019 & 187 & 2.84 & 1.134 & .083 \\
\hline \multirow[t]{2}{*}{ Resin Bonded Bridge } & 2016 & 153 & 2.79 & 1.286 & .104 \\
\hline & 2019 & 190 & 2.87 & 1.145 & .083 \\
\hline \multirow[t]{2}{*}{ Inlay } & 2016 & 153 & 2.22 & 1.131 & .091 \\
\hline & 2019 & 191 & 2.75 & 1.119 & .081 \\
\hline
\end{tabular}




\begin{tabular}{llllll} 
Onlay & 2016 & 153 & 2.18 & 1.155 & .093 \\
\cline { 2 - 6 } & 2019 & 191 & 2.76 & 1.148 & .083 \\
\hline Management of pulp exposure & 2016 & 153 & 3.50 & 1.176 & .095 \\
\cline { 2 - 6 } & 2019 & 192 & 3.43 & 1.086 & .078
\end{tabular}

\section{Discussion}

Competency is the ability to combine evidence based knowledge, personal attitudes, and clinical skills to undertake holistic dental care $[16,17]$. Competency may be of greater relevance to the dental practice than confidence level, however, the role of confidence in achieving competence should not be underestimated [18]. The quality of education and the clinical experience are essential in determining the confidence level of dental students [12]. Hence, the implementation of competencies in the curricula of undergraduate dental students was to support them to develop capacity to become safe practitioners, and as tool to update and develop curricula [3-7]. Prosthodontics and conservative dentistry are one of the core disciplines in dental practice, general practitioners usually encounter simple and complicated cases after graduation. Consequently, general dentists' practitioners should have the ability to evaluate and diagnose properly based on their understanding and knowledge, and to perform adequate procedures, especially simple cases.

Surveys are considered an essential technique to evaluate students' perceptions and to gather information in a way that allows us, as educators, to address the successfulness and the limitations of the educational experience [19-21]. This study aims assess the perception and confidence level of final year dental students in performing essential dental procedures from core dental disciplines;

Prosthodontics and Conservative dentistry. Through comparing their perceived confidence level in to two different years, 2016 and 2019.

Competencies were introduced at the first time in our dental students' curriculum in 2017, it includes multiple tasks that students are able to try to fulfil independently without supervision, for example in Prosthodontic clinics students were entitled to choose two out of multiple tasks for each semester, for example, border molding and final impression for edentulous patient, surveying of primary cast and Cr-Co RPD design, bite registration for edentulous patient. In addition, competencies were not graded which means either pass or fail, however, their fulfilment is a requirement for entering the clinical final exam at the end of the fifth year, all of that is to encourage students to do dental procedures with more confidence. Competencies is part of the 4th and the fifth year students, but most of the requirements and competencies are in the final year, because of that the fifth year students were chosen for this study.

In the present study by comparing the means of confidence level of the different tasks, students showed high confidence levels in doing simple procedures in both years, like providing patients with simple removable prosthesis (CD, Acrylic RPD, Cr-Co RPD), treatment planning for partially edentulous patients, placement of amalgam and composite filings, single crown PFM and three-units bridge. The same results 
reported in previous studies [18,22-24], Murray showed in his study on final year students from New Zealand that $68.4 \%$ of students were highly confident/confident in providing patients with acrylic RPD, $59.6 \%$ in providing Full CD, $84.5 \%$ and $77.6 \%$ in providing anterior and posterior composite restoration respectively, $47.4 \%$ in conventional bridge preparation, $87.8 \%$ in Crown preparation. The same applies for the low level of confidence which was mainly in more complex procedures, like providing the patient with Immediate or Over Dentures, Implant retained prosthesis, Inlay, Onlay, Veneers and Resin Bonded Bridges. In another recent study carried in the same faculty, $97 \%$ of the fifth year students felt extremely confident in doing direct restorations while their confidence level was significantly lower in doing indirect restorations [25]. This could be related to the concept of a "safe beginner" who acts within the boundaries of their own capabilities and limitations, and knows when to request support and advice, although it has been suggested that this definition lacks both precision and detail [26]. Moreover, the only clinical training students were exposed to is during their undergrad period of time, afterwards they need to do clinical Internship for a year before they can practice independently, consequently their confidence level in more complex procedures is supposed to increase, because clinical training one of the main factors that affects students' confidence level $[12,18,27]$. The involvement of the fifth year student only in this study considered one of the limitations, because of the limited clinical training time, however, this may be considered in future research to apply the same survey after the internship period and compare results to confirm the effect of clinical on the confidence level of freshly graduate students.

To assess the effect of competencies implementation in the curricula of dental students, the confidence level in dental procedure is compared between the two years. In prosthodontic procedures there was no significant difference between the confidence levels of different procedures, except for Placing treatment plan of RPD, giving OHI's for Denture Patients, and dealing with CD post-insertion complaints were the confidence level of 2016 student was significantly higher than $2019(P<.05)$. In Conservative procedures, there was no significant difference between the confidence levels of different procedures, except for Placement of the Matrix Band in Class II restoration, the confidence level of 2016 students was significantly higher than 2019. This opposite to the assumption that competencies might have a positive effect on the confidence level of students, but it is only in four out of 36 procedures tested in this survey. Achieving self-confidence is an important asset in enhancing the competencies [28], but to avoid students being over-confident they need to learn how to self-evaluate their performance, this ability to self-evaluate and achieve the real confidence needed is best achieved by independent clinical practice and implementing a proper methods for the evaluation of competencies during the undergraduate training; Kaufman et al. stated that learners should be able to analyze and assess their own performance and develop new perspectives and options [29]. The results in this study may be explained by the methods used for the evaluation of the competencies and by the set-up of competencies besides the requirements needed from fifth year students to successfully graduate. Competencies can be evaluated by a number of methods, traditional and current methods [30]. The methods used for evaluation in our dental school are traditional methods, students are entitled to do competencies during their clinical training, the task must be done independently in a specific period of time, then task is subjectively evaluated by two evaluators and the evaluation is including a short viva questions about the same procedure to assess the student 
knowledge. The traditional method had a major drawback in that it was subjective and occasionally inflexible, while newer criteria looks objectively at assessing the student. Consequently, competencies implantation in students' curricula must be revaluated to achieve the intended learning outcomes.

\section{Conclusion}

In summary, this study has shown that final year dental students in the University of Jordan are more or less similar in their confidence profile with their counterparts in other parts of the world, they have high confidence level in doing simple dental procedures and less confident in more complex ones. Their confidence level may increase once they finish their Internship training especially with complex procedures, hence this study may help in further monitoring them during this period of time. For those clinical tasks where the majority of students were lacking in confidence, opportunities for further experience within the dental school setting might be helpful.

Competency-based dental education is a continuous process in maintaining a degree of quality consistent with patient well-being and effective treatment management path, which the graduating dentist should achieve. However, competency implementation and execution criteria may differ through schools which may effect on final outcomes. Hence, regular evaluation of competencies is needed, because it is important that students are assessed properly to become safe dentists and to meet the minimum global standards.

\section{Abbreviations}

OHI: oral hygiene instructions; RPD: removable partial dentures; CD: complete denture; SPSS: Statistical Package for Social Science; Co-Cr: Cobalt-Chromium

\section{Declarations}

\section{Ethics approval and consent to participate}

This study was performed in accordance with the provisions of the Declaration of Helsinki. This study was reviewed and approved by the Institutional Review Board/Deanship of Scientific Research of the University of Jordan (Ref \# 9-2019). All participants provided informed consent prior to participation in the study.

\section{Consent for publication}

Not applicable.

\section{Availability of data and material}

The dataset used and analyzed during the current study can be shared by the corresponding author upon reasonable request. 


\section{Competing interests}

The authors declare that they have no competing interest associated with this study.

\section{Funding}

This research received no specific grant from any funding agency in public, commercial, or nonprofit sectors.

\section{Authors' contributions}

All authors were responsible for the study design and development of the questionnaire. All authors made substantial contributions to the conception of the work. All authors made substantial contributions to the data collection. All authors analyzed and interpreted the data. All authors were the major contributors in writing the manuscript. All authors read and approved the final manuscript.

\section{Acknowledgements}

We thank Prof. Mahmoud Al-Hussami for his contribution in the statistical analysis and the proofreading of the manuscript. We are grateful to all the participants in this study. This study was conducted at the School of Dentistry of the University of Jordan.

\section{References}

1. Koole, S., et al., Implant dentistry education in E urope: 5 years after the A ssociation for $D$ ental $E$ ducation in E urope consensus report. European journal of dental education, 2014. 18: p. 43-51.

2. Clark, J., L. Robertson, and R. Harden, Applying learning outcomes to dental education. British dental journal, 2004. 196(6): p. 357-359.

3. Association, A.D.E., ADEA foundation knowledge and skills for the new general dentist. J Dent Educ, 2011. 75(7): p. 936-40.

4. Association, A.D.E., ADEA Competencies for the New General Dentist "As approved by the 2008 ADEA House of Delegates.". J. Dent. Educ, 2011. 75(7): p. 932-935.

5. Cowpe, J., et al., Profile and competences for the graduating European dentist-update 2009. European Journal of Dental Education, 2010. 14(4): p. 193-202.

6. Gerrow, J.D., H.J. Murphy, and M.A. Boyd, Review and revision of the competencies for a beginning dental practitioner in Canada. Journal of the Canadian Dental Association, 2007. 73(2).

7. Council, A.D., Professional attributes and competencies of the newly qualified dentist. Australian Dental Council June 2010.

8. Hsu, T.-C., et al., Core clinical competencies for dental graduates in Taiwan: Considering local and cultural issues. Journal of Dental Sciences, 2015. 10(2): p. 161-166. 
9. Koole, S., et al., Competence profiles in undergraduate dental education: a comparison between theory and reality. BMC oral health, 2017. 17(1): p. 1-8.

10. Hunt, R.J. and M. Bushong, ADEA CCI vision focuses on preparing graduates for discoveries of the future. Journal of dental education, 2010. 74(8): p. 819-823.

11. Walsh, L., Education of professionals-is there a role for a competency-based approach. Effective teaching at University and Reflection on practiceThe University of Queensland, Teaching and Educational Development Institute, Women's College University of Queensland, 1999.

12. Puryer, J., et al., The confidence of undergraduate dental students when carrying out prosthodontic treatment and their perception of the quality of prosthodontic education. European Journal of Dental Education, 2018. 22(1): p. e142-e148.

13. Gilmour, A., et al., The undergraduate preparation of dentists: Confidence levels of final year dental students at the School of Dentistry in Cardiff. British dental journal, 2016. 221(6): p. 349-354.

14. Packer, M., B. Scott, and D. Davis, An assessment of the influence of clinical demonstrations on the confidence of undergraduate dental students, when treating patients requiring removable partial dentures. European Journal of Dental Education, 1999. 3(3): p. 133-139.

15. Patel, J., et al., Undergraduate training as preparation for vocational training in England: a survey of vocational dental practitioners' and their trainers' views. British dental journal, 2006. 201(5): p. 9-15.

16. Licari, F.W. and D.W. Chambers, Some paradoxes in competency-based dental education. J Dent Educ, 2008. 72(1): p. 8-18.

17. Chambers, D.W., Toward a competency-based curriculum. J Dent Educ, 1993. 57(11): p. 790-3.

18. Honey, J., et al., Ready for practice? A study of confidence levels of final year dental students at Cardiff University and University College Cork. Eur J Dent Educ, 2011. 15(2): p. 98-103.

19. Henzi, D., et al., Appraisal of the dental school learning environment: the students' view. J Dent Educ, 2005. 69(10): p. 1137-47.

20. Rolland, S., R. Hobson, and S. Hanwell, Clinical competency exercises: some student perceptions. Eur J Dent Educ, 2007. 11(3): p. 184-91.

21. Henzi, D., et al., North American dental students' perspectives about their clinical education. J Dent Educ, 2006. 70(4): p. 361-77.

22. Ali, K., et al., Preparedness of dental graduates for foundation training: a qualitative study. British Dental Journal, 2014. 217(3): p. 145-149.

23. Bartlett, D.W., et al., Experiences and perceptions of vocational training reported by the 1999 cohort of vocational dental practitioners and their trainers in England and Wales. Br Dent J, 2001. 191(5): p. $265-70$.

24. Murray, C. and N. Chandler, Final year dental students in New Zealand: Self-reported confidence levels prior to BDS graduation. N Z Dent J, 2016. 112(4): p. 116-121.

25. Hattar, S., et al., Dental students' experience and perceived confidence level in different restorative procedures. Eur J Dent Educ, 2021. 25(1): p. 207-214. 
26. Bateman, H., et al., Developing assessment: involving the sessional clinical teacher. Br Dent J, 2016. 220(3): p. 129-32.

27. Murray, F.J., A.S. Blinkhorn, and J. Bulman, An assessment of the views held by recent graduates on their undergraduate course. Eur J Dent Educ, 1999. 3(1): p. 3-9.

28. Wanigasooriya, N., Student self-assessment of essential skills in dental surgery. Br Dent J, 2004. Suppl: p. $11-4$.

29. Kaufman, D.M., Applying educational theory in practice. BMJ, 2003. 326(7382): p. 213-216.

30. Manakil, J. and R. George, Reviewing competency in dental education. International Journal of dental clinics, 2011. 3(2): p. 33-39.

\section{Figures}
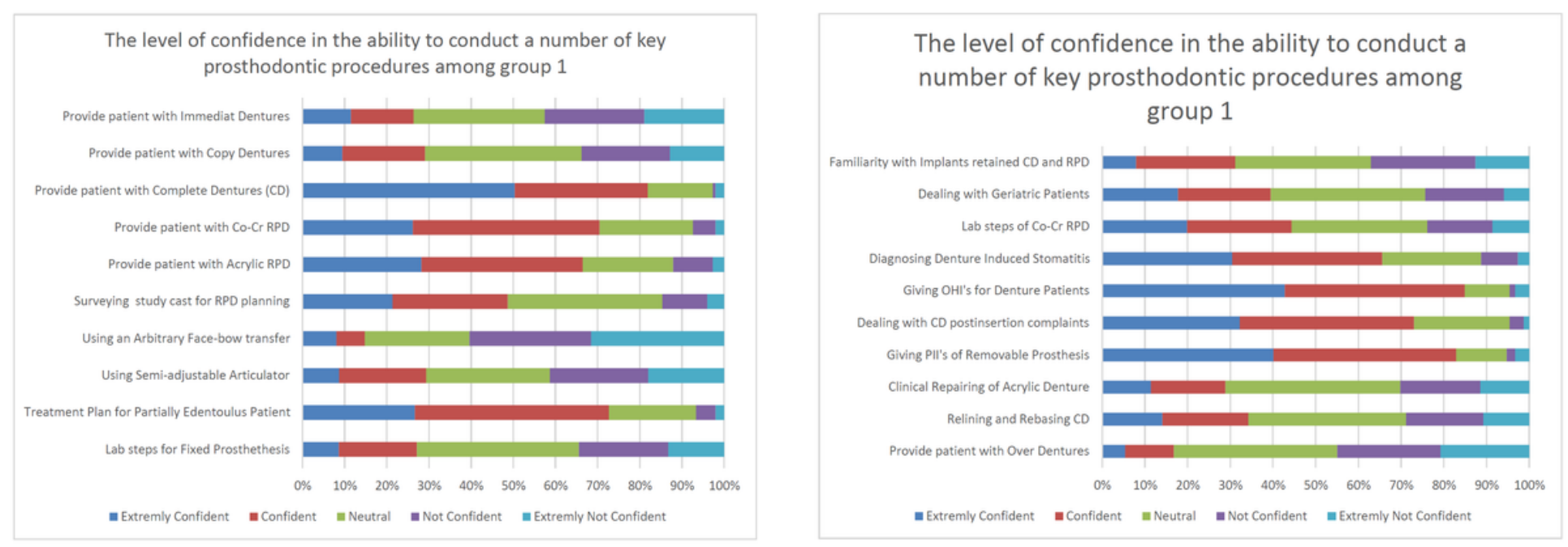

Figure 1

a: The level of confidence in the ability to conduct a number of key prosthodontic procedures among group $1 \mathrm{~b}$ : The level of confidence in the ability to conduct a number of key prosthodontic procedures among group 1 

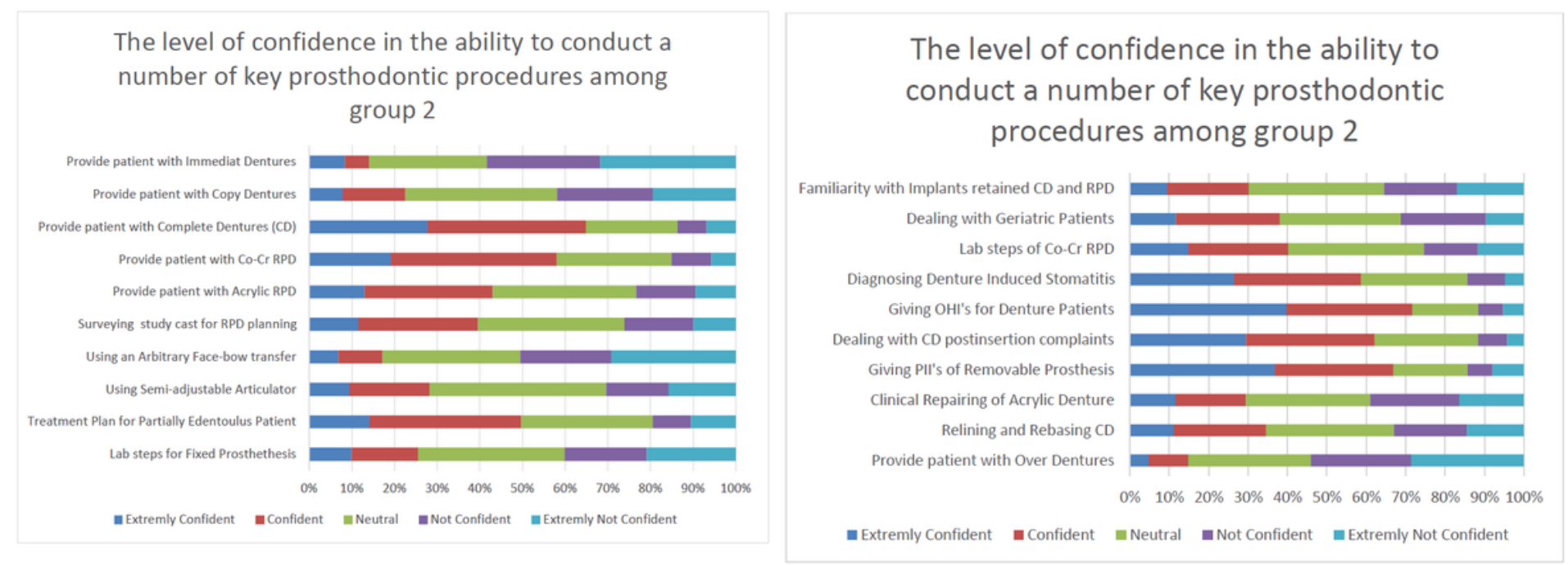

\section{Figure 2}

a: The level of confidence in the ability to conduct a number of key prosthodontic procedures among group $2 \mathrm{~b}$ : The level of confidence in the ability to conduct a number of key prosthodontic procedures among group 2
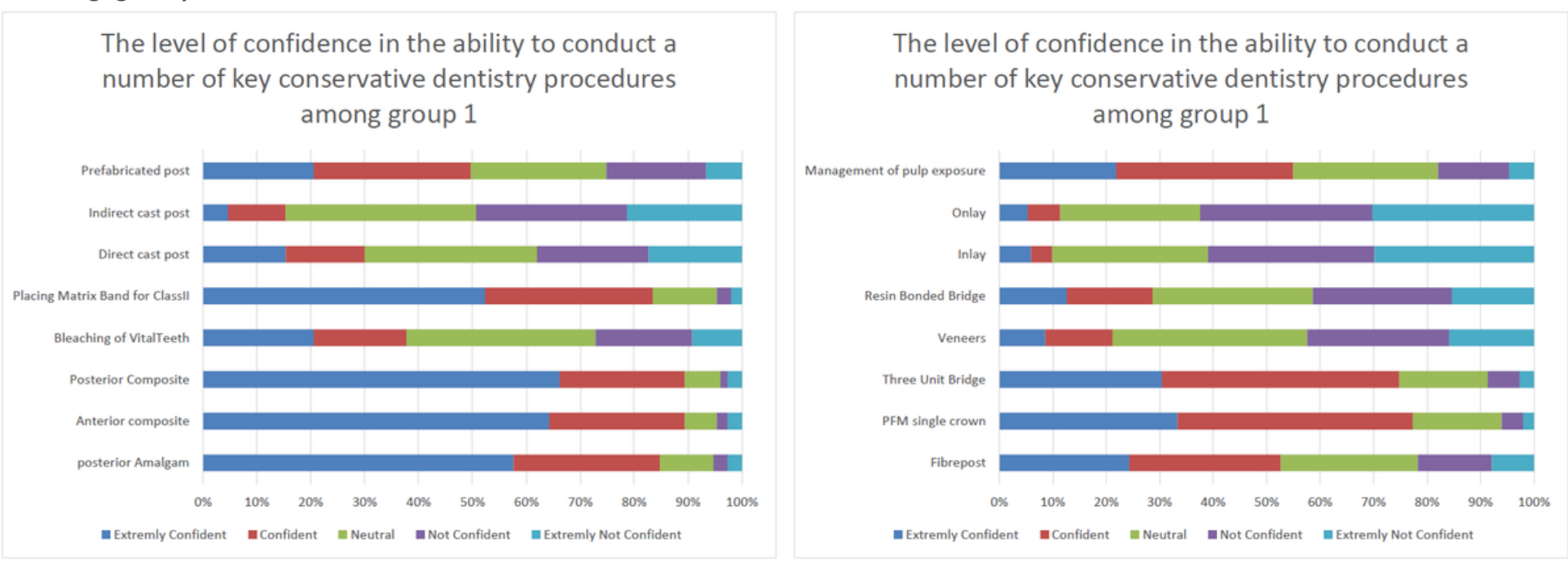

\section{Figure 3}

a: The level of confidence in the ability to conduct a number of key conservative procedures among group $1 \mathrm{~b}$ : The level of confidence in the ability to conduct a number of key conservative procedures among group 1 

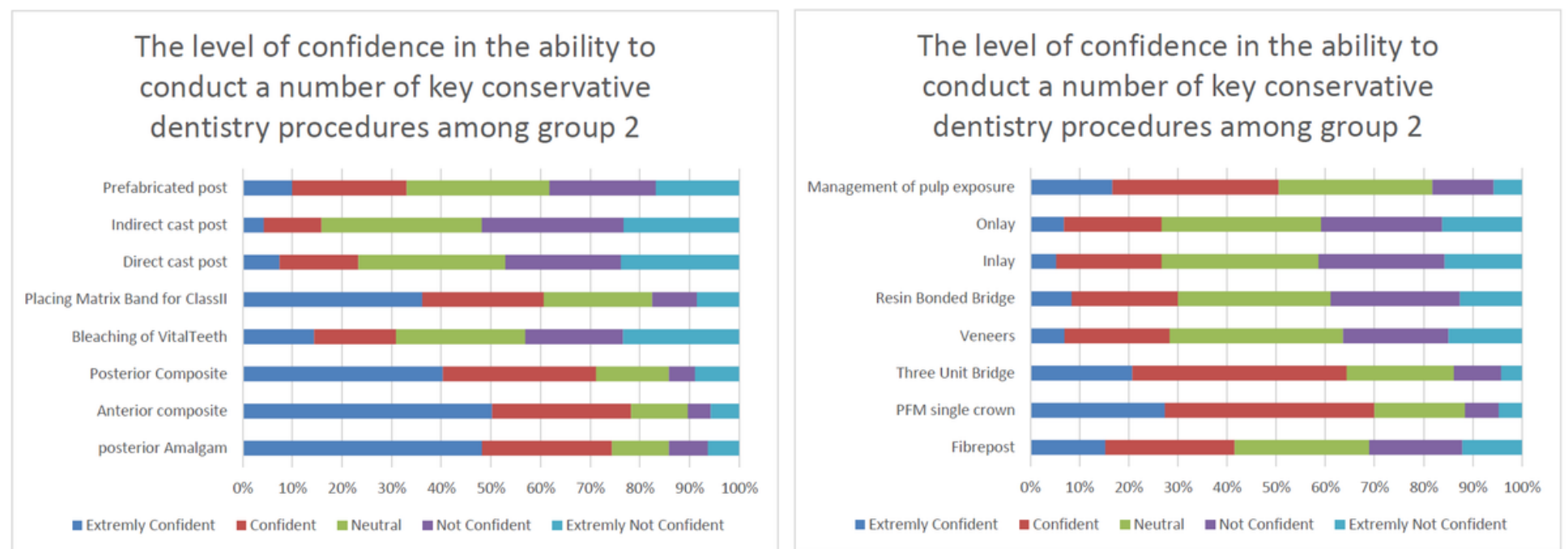

Figure 4

a: The level of confidence in the ability to conduct a number of key conservative procedures among group $2 \mathrm{~b}$ : The level of confidence in the ability to conduct a number of key conservative procedures among group 2 